\title{
Serological and Biological Studies of Blood in Forensic Investigations
}

\author{
Greeshma Gopisetti* and Ananya Guduru \\ Department of Biotechnology, Jawaharlal Nehru Technological University Hyderabad, India
}

\begin{abstract}
The serological methods are primary methods in forensic investigations. Scientific methods using immunological reaction, chemical methods, the serological test methods are considered to be the most important to confirm the results of investigations. Basic element for any study is blood, and the science of bloodstain analysis traditionally follows certain steps which adequately describe the various tests conducted.Blood retrieved from stained cloth, stained earth samples, the weapons used etc., acquired from crime scene are to be collected for sampling. The origin of the sample whether it is of human or animal to be ascertained. Here, an effort is made to review the use ofblood in serological tests on the biological materials available at the crime scene.
\end{abstract}

Keywords: Serology, Blood sample, Forensic studies

\section{Introduction}

In 1901, Karl Land Steiner announced one of the most significant discoveries of the century-the typing of blood-a finding that won him a Nobel Prize after 29 years [1]. The most important biological fluids to identify in the form of stains in criminal cases are blood. Blood is the most common, well-known and perhaps most important evidence in the world of criminal justice today.

One of the first steps in the analysis of forensic evidence is the search for biological material that can subsequently be used for DNA extraction and profiling. Many types of body fluids on forensic evidence, originating from suspect or victim, can be used for DNA profiling, such as blood, semen, saliva, vaginal fluid, urine, and sweat [2]. Blood is a common body fluid detected on pieces of evidence found at crime scenes, especially at scenes of violent crimes. Before DNA profiling can be performed, the presence of a potential biological stain, for example, blood, needs to be visually detected. White light and the visible eye or a low-power microscope can be used for a standard examination of an item of clothing. However, when blood is present on a dark background, for example, a dark fabric, it might be invisible for the naked eye. Several visualization, presumptive, and confirmatory blood tests have been developed and evaluated [3-9]. The potential presence of blood on a dark background can be visualized by an alternate light source such as Polilight $[10,11]$.

\section{Materials and Methods}

\section{Detection of blood in stains}

\section{Preliminary screening tests}

Principles

There tests are based on the observation that blood hemoglobin possesses peroxidase-like activity. peroxidases are enzymes that accelerate the oxidation of several classes of organic compounds by peroxides. When a colorless reagent and hydrogen peroxide are added to the blood stain,

*Correspondence to: Gopisetti Greeshma, Department of Biotechnology, Jawaharlal Nehru Technological University Hyderabad, India, E-mail: gn_greeshma@ yahoo.com

Citation: Gopisetti G, Guduru A (2020) Serological and Biological Studies of Blood in Forensic Investigations. J Clin Anat Pathol, 5(1): 104. DOI: https://doi. org/10.47275/2332-4864-104.

Received: June 08, 2020; Accepted: June 30, 2020; Published: July 05, 2020

Copyright: $\odot 2020$ Gopisetti G, et al. This is an Open Access article distributed under the terms of the Creative Commons Attribution 4.0 International License (CCBY) (http://creativecommons.org/licenses/by/4.0/) which permits commercial use, including reproduction, adaptation, and distribution of the article provided the original author and source are credited. 
the hemoglobin in blood will cause the formation of different colors. In luminal test the presence of blood is indicated by luminescence. Several methods as detailed below are practiced for detecting blood, present in minute quantities. Among them, Benzedine test is used in the laboratory.

\section{Benzidine test}

A small piece of stained thread or a small quality of stained material is taken on a white glazed porcelain tile.Two drops of benzidine reagent are added.Mixture is allowed to react for half a minute.Few drops of hydrogen peroxide are added (Figure 1).

\section{Conclusion}

The presence of blood is indicated by the development of intense bluish green color almost immediately

\section{Confirmation test of blood}

The presence of haemoglobin and its derivatives in blood stains indicated by the screening test is confirmed by any of the following tests.

\section{Principle}

These tests are based on the formation of crystals by haemogolobin derivatives. Haemen and Haemochoromogen with different salts (acetate and nitrogen bases) in acidic or alkaline aqueous medium.

Two types of confirmatory tests are in use and are as described as:-

\section{Teichmantest (Haemen Test)}

A stain portion is taken in a porcelain dish and socked in normal saline for few minute and a few drops of acetone are added.One drop of the extract is taken on the microscope slide.A drop of $10 \%$ Hydrochloric acid is added to it.The mixture is covered with a cover slip and observed under the microscope (Figure 2).

\section{Conclusion}

Brown rhombohedron shaped acetone chlor-haemin crystals are seen confirming the blood.

\section{Haemochromogentest (Takayama Test)}

A stained portion is taken in a porcelain dish and socked in normal saline for few minute.One drop of the extract is taken on microscope slide. One or two drops of Takayama reagent are added. The mixture is covered with a cover slip and warmed gently and allowed to cool. Examine under the microscope (Figure 3).
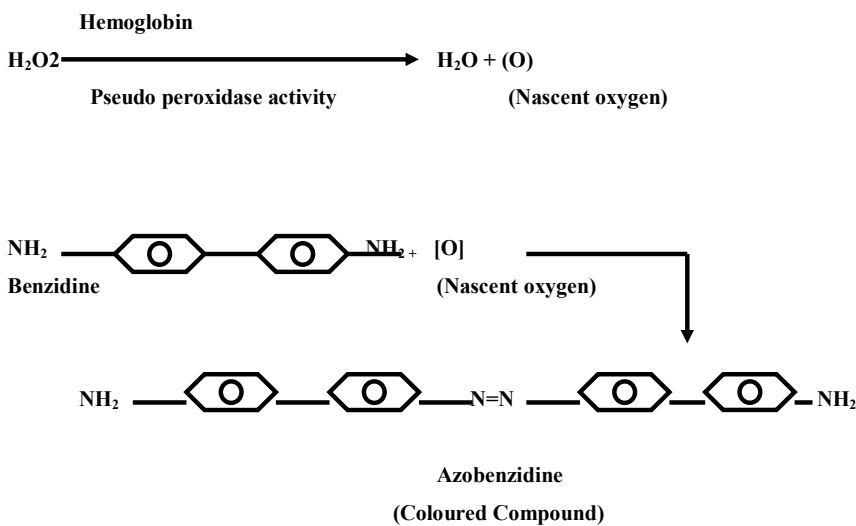

Figure 1: Benzidine test reaction mechanism.

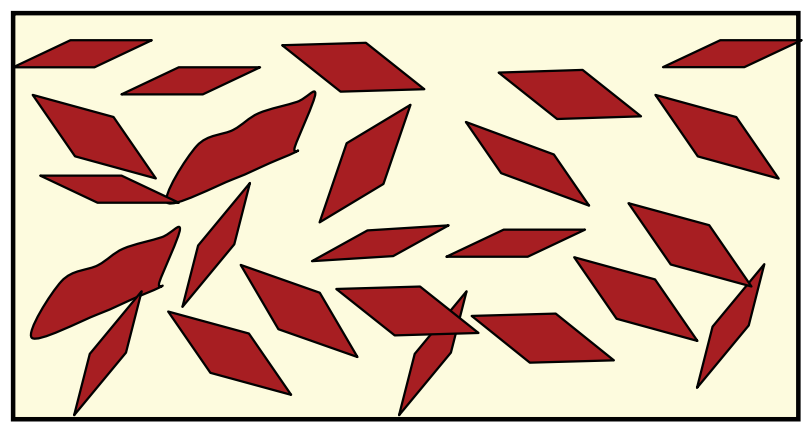

Figure 2: Haemin crystals. 


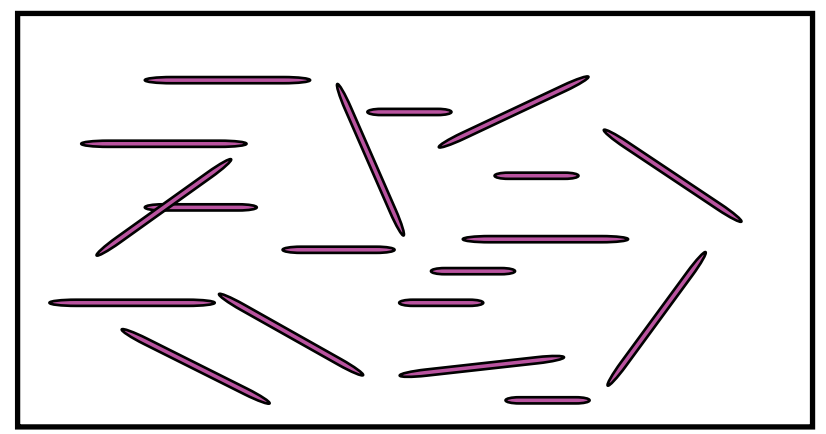

Figure 3: Haemochromogen crystals.

\section{Conclusion}

Salmon, pink colour niddle shaped crystal of pyridine haemochr-omogen are observed under microscope confirming the presence of blood.

\section{References}

1. Landsteiner K. 2001. Agglutination phenomena of normal human blood. Wien KlinWochenschr 113(20-21): 768-769.PMID: 11732110

2. Virkler K, Lednev IK. 2009. Analysis of body fluids for forensic purposes: from laboratory testing to non-destructive rapid confirmatory identification at a crime scene. Forensic Sci Int 188(1-3):1-17.https://doi.org/10.1016/j.forsciint.2009.02.013

3. Cox M. 1991. A study of the sensitivity and specificity of four presumptive tests for blood. J Forensic Sci 36(5):1503-1511.PMID: 1955838

4. Budowle B, Leggitt JL, Defenbaugh DA, Keys KM, Malkiewicz SF. 2000. The presumptive reagent fluorescein for detection of dilute bloodstains and subsequent STR typing of recovered DNA. J Forensic Sci 45(5):1090-1092.PMID: 11005186

5. Gross AM, Harris KA, Kaldun GL. 1999. The effect of luminol on presumptive tests and DNA analysis using the polymerase chain reaction. J Forensic Sci 44(4):837-840.PMID: 10432617

6. Spalding R. 2003. Identification and characterization of blood and bloodstains. In: James SH, Nordby JJ, Bell S, (eds) Forensic science: an introduction to scientific and investigativetechniques. CRC Press, Boca Raton, FL, USA, pp 181-201.

7. Cheeseman R, DiMeo LA. 1995. Fluorescein as a field-worthy latent bloodstain detection system. J Forensic Identif 45(6):631-646.

8. Jakovich CJ. 2007. STR analysis following latent blood detection by Luminol, Fluorescein, and BlueStar. J Forensic Identif 57(2):193-198.

9. Edelman GJ, Hoveling RJ, Roos M, van Leeuwen TG, Aalders MC. 2013. Infrared imaging of the crime scene: possibilities and pitfalls. J Forensic Sci 58(5):1156-1162.https://doi. org/10.1111/1556-4029.12225

10. Vandenberg N, van Oorschot RA. 2006. The use of Polilight in the detection of seminal fluid, saliva, and bloodstains and comparison with conventional chemical-based screening tests.J Forensic Sci 51(2):361-370.https://doi.org/10.1111/j.1556-4029.2007.00437.x

11. Shaler R. 2002. Modern forensic biology. In: Saferstein R, (ed) Forensic science handbook. Upper Saddle River, NJ, USA, pp 529-546. 